\title{
BMJ Open Association between body mass index and short-term mortality in patients with intra-abdominal infections: a retrospective, single-centre cohort study using the Medical Information Mart for Intensive Care database
}

Qinglin Li, ${ }^{1}$ Yingmu Tong, ${ }^{1}$ Sinan Liu, ${ }^{1,2}$ Kaibo Yang, ${ }^{1}$ Chang Liu, ${ }^{1,2}$ Jingyao Zhang (D) ${ }^{1,2}$

To cite: Li Q, Tong Y, Liu S, et al. Association between body mass index and shortterm mortality in patients with intra-abdominal infections: a retrospective, single-centre cohort study using the Medical Information Mart for Intensive Care database. BMJ Open 2021;11:e046623. doi:10.1136/ bmjopen-2020-046623

- Prepublication history and additional supplemental material for this paper are available online. To view these files, please visit the journal online. (http://dx.doi.org/10.1136/ bmjopen-2020-046623).

Received 06 November 2020 Accepted 31 July 2021

Check for updates

(c) Author(s) (or their employer(s)) 2021. Re-use permitted under CC BY-NC. No commercial re-use. See rights and permissions. Published by BMJ.

${ }^{1}$ Department of Hepatobiliary Surgery, The First Affiliated Hospital of Xi'an Jiaotong University, Xi'an, Shaanxi, China ${ }^{2}$ Department of SICU, The First Affiliated Hospital of Xi'an Jiaotong University, Xi'an, Shaanxi, China

Correspondence to Dr Jingyao Zhang; you120uy@163.com and Professor Chang Liu; liuchangdoctor@163.com

\section{ABSTRACT}

Objectives This study aimed to determine the relationship between the body mass index (BMI) and short-term mortality of patients with intra-abdominal infection (IAI) using the Medical Information Mart for Intensive Care (MIMIC-III) database.

Design Retrospective cohort study.

Setting Adult intensive care units (ICUs) at a tertiary hospital in the USA.

Participants Adult IAI ICU patients from 2001 to 2012 in the MIMIC-III database.

Interventions In univariate analysis, we compared the differences in the characteristics of patients in each BMI group. Cox regression models were used to evaluate the relationships between BMI and short-term prognosis.

Primary and secondary outcome measures 90-day survival.

Results In total, 1161 patients with IAI were included. There were 399 (34.4\%) patients with a normal BMl $\left(<25 \mathrm{~kg} / \mathrm{m}^{2}\right), 357(30.8 \%)$ overweight patients $(25-30 \mathrm{~kg} /$ $\left.\mathrm{m}^{2}\right)$ and $405(34.9 \%)$ obese patients $\left(>30 \mathrm{~kg} / \mathrm{m}^{2}\right)$ who tended to be younger $(p<0.001)$ and had higher Sequential Organ Failure Assessment scores $(p<0.05)$. The mortality of obese patients at 90 days was lower than that of patients with a normal BMI $(20.74 \%$ vs $23.25 \%$, $p<0.05)$, but their length of stay in the ICU was higher (4.9 days vs 3.6 days, $p<0.001$ ); however, their rate of mechanical ventilation utilisation was higher $(61.48 \%$ vs $56.86 \%$, $\mathrm{p}<0.05)$. In the Cox regression model, we also confirmed that BMI was a protective factor in patients with IAls, and the adjusted mortality rate of patients with a higher BMI was 0.97 times lower than that of patients with a lower BMI ( $p<0.001, H R=0.97,95 \% \mathrm{Cl} 0.96$ to 0.99 ).

Conclusions IAl patients with an overweight or obese status might have lower 90 -day mortality than patients with a normal BMI.

\section{INTRODUCTION}

Intra-abdominal infections (IAIs) are common surgical emergencies and have been

\section{STRENGTHS AND LIMITATIONS OF THIS STUDY}

$\Rightarrow$ To our knowledge, this is the first study to evaluate the association between body mass index (BMI) and the short-term mortality of patients with abdominal infection.

$\Rightarrow$ Multiple imputation was used to handle the missing values.

$\Rightarrow$ This study is essentially a retrospective singlecentre study, which makes it difficult to completely exclude the influence of residual confounding factors.

$\Rightarrow$ A considerable number of patients' data are missing, especially various laboratory test data, which may cause selection bias.

$\Rightarrow$ Given the observational nature of this study, we can not determine causality between the BMI and mortality.

reported as major contributors to non-trauma deaths in emergency departments worldwide and a common complication of abdominal surgery. ${ }^{1}$ IAIs are the second most common cause of sepsis, and the second most common infectious disease among inpatients. The death rate of IAIs can reach $20 \%$, indicating a common poor prognosis in patients. ${ }^{2} 3$ IAIs can be divided into uncomplicated and complicated types. Uncomplicated IAIs affect a single organ, and complicated IAIs describe an extension of the infection into the peritoneal space. The resultant physiological response may develop into a systemic inflammatory response syndrome (SIRS). ${ }^{4}$

The body mass index (BMI), calculated as the weight divided by the square of the height, is used by most health organisations, including the WHO, as a screening tool for diagnosing obesity. ${ }^{5}$ Overweight and obesity 
are uniformly associated with a substantially increased risk of death. ${ }^{6}$ In patients not admitted to the intensive care unit (ICU), such as endometrial and patients with breast cancer, BMI can be used as a prognostic indicator. ${ }^{78}$ Similarly, in ICU patients, such as liver transplant patients, morbid obesity has an impact on patient survival and post-transplant complications. ${ }^{9}$ Furthermore, at least a quarter of patients in the USA. ICUs have a BMI indicating overweight, obesity or morbid obesity status. ${ }^{10}$ As mentioned earlier, patients with IAIs also tend to develop severe conditions and were admitted to the ICU. Previous studies have shown that obesity plays a protective role in some diseases (such as chronic kidney disease, AIDS), which is a special phenomenon called the obesity paradox. ${ }^{11}{ }^{12}$ However, in ICU patients with IAIs, whether $\mathrm{BMI}$ is a risk factor or a protective factor, considering the obesity paradox, still needs further study.

This study was aimed to determine the relationship between BMI and the 90-day mortality of patients with IAIs using the Medical Information Mart for Intensive Care (MIMIC-III) database. ${ }^{13}$ The MIMIC-III database is a large, single-centre database comprising information related to patients admitted to critical care units at a large tertiary care hospital. Data included vital signs, medications, laboratory measurements, diagnostic codes, hospital length of stay (LOS), survival data and so on. The data cover 53423 distinct hospital admissions for adult patients admitted to critical care units between 2001 and 2012, and many studies have been conducted to explore the clinical features of ICU patients using the database. $^{14-16}$

\section{MATERIALS AND METHODS Database}

In this article, we did a retrospective cohort study using a publicly available critical care medicine database, MIMIC-III. This database contains unidentified medical information from 53423 patients admitted to the critical care units of the Beth Israel Deaconess Medical Center in Boston, Massachusetts, from 2001 to 2012. The database was maintained by the Laboratory for Computational Physiology at the Massachusetts Institute of Technology (MIT). In MIMIC database, all diagnostics correspond to International Classification of Diseases (ICD-9) codes. ${ }^{13}$

\section{Study population}

There is no specific IAI diagnosis in ICD-9 coding; therefore, we included all the possible diagnoses related to IAIs in ICD-9 into our study cohort, and all ICD-9 codes, diagnostics and numbers of specific diagnoses are listed in online supplemental table 1. For patients who had multiple ICU admissions, only the first admission record was kept. The exclusion criteria were as follows: (1) those under 18 years old and (2) missing weight data. According to the BMI classification standard of the WHO, we divided the patients into five groups: underweight (BMI: $<18.5 \mathrm{~kg} /$ $\mathrm{m}^{2}$ ), normal weight (BMI: 18.5 to $<25 \mathrm{~kg} / \mathrm{m}^{2}$ ), overweight
(BMI: 25 to $<30 \mathrm{~kg} / \mathrm{m}^{2}$ ), obese (BMI: 30 to $<40 \mathrm{~kg} / \mathrm{m}^{2}$ ) and morbidly obese (BMI: $>40 \mathrm{~kg} / \mathrm{m}^{2}$ ). However, in this grouping method, the number of patients in the underweight and morbidly obese subgroups was not sufficient ( $\mathrm{n}=27$ and 54, respectively, as shown in online supplemental figure 1). Finally, all patients were divided into three groups: normal BMI group (BMI $<25 \mathrm{~kg} / \mathrm{m}^{2}$ ), overweight BMI group $\left(25-30 \mathrm{~kg} / \mathrm{m}^{2}\right)$ and obese BMI group $\left(\right.$ BMI $\left.>30 \mathrm{~kg} / \mathrm{m}^{2}\right)$.

\section{Data extraction and management}

We used the Structure Query Language in PostgreSQL (V.9.5) to retrieve the data. The following data were extracted from the MIMIC-III database on the first day of ICU admission: age; sex; ethnicity; admission weight; admission height; admission diagnosis; admission type; Sequential Organ Failure Assessment (SOFA) score; Simplified Acute Physiology Score II (SAPSII); Charlson Comorbidity Index; use of vasopressors; renal replacement therapy; mechanical ventilation use; values of haemoglobin (HGB); white cell (WBC); platelet count (PLT); albumin (ALB); sodium (Na); chlorine (Cl); potassium (K); creatinine (CRE); blood urea nitrogen (BUN); glucose (GLU); lactate (LAC) and bilirubin (BIL) levels in the first 24 hours of ICU admission; LOS before ICU admission; LOS (both ICU and hospital); intake and output. The SOFA score was calculated within the first 24 hours after ICU admission. If a variable was measured more than once in the first 24 hours, the value that indicated a worse prognosis was used. In addition, dates of birth for patients aged over 89 years were moved to obscure their true age and comply with Health Insurance Portability and Accountability Act (HIPAA) regulations: these patients appear in the database with ages of over 300 years, but the median age of these patients was 91.5 years, so we modified their age to 91.5 years.

\section{Outcomes}

The primary endings were the 90-day mortality after ICU admission.

\section{Patient and public involvement}

We did not need patient consent or ethics approval, as all data were deidentified.

\section{Statistical analysis}

First, univariate analysis was used to compare all variables. If the data satisfied a normal distribution and the variance was homogeneous, the data were expressed as the mean \pm SD, and Student's t-test was used for comparisons. If the variance was not homogeneous, one-way analysis of variance (ANOVA) was used for the comparisons. If none of the above requirements were met or the data were not continuous variables, then the data were described as the median and IQR, and the Wilcoxon rank-sum test was used for comparisons. Categorical variables were presented as numbers and percentages and compared using Pearson's $\chi^{2}$ test or Fisher's exact test as appropriate. We used the log-rank test and 90-day Kaplan-Meier (K-M) curves to 
carry out the survival analysis, and determined whether BMI was associated with 90-day mortality. In addition, we compared the 90-day survival curves between subgroups of patients with and without sepsis using log-rank test.

Propensity score matching (PSM) was performed to minimise the influence of confounding factors on selection bias. The propensity scores were elicited from matched patients in a 1:1 ratio with greedy matching algorithms without replacement. We adjusted for age, gender, admission type, ethnicity, marital status and insurance type.

We used multiple imputation (MI), based on five replications and a chained equation approach method in the R STUDIO MI procedure, to account for missing data on height and the missing laboratory test. ${ }^{17}$ Multivariate analyses were adjusted for the possible variables that may affect the prognosis of patients to determine the relationship between BMI and 90- day mortality.

We tested the collinearity of the variables included in the statistical analysis, and found that the variance inflation factor of all variables was $<3$; hence, there was no statistical collinearity in the included variables.

Variables with $\mathrm{p}<0.10$ in univariate analysis were included in the Cox regression model as confounders to determine whether BMI was the independent risk factor of the 90-day survival rates. However, since SOFA scores included BIL and CRE level, PLT count, mechanical ventilation use and vasoactive drug use, and Charlson Comorbidity Index includes comorbidity, to avoid instability of the model caused by collinearity among variables, we did not adjust these variables in the statistical analysis.

SPSS (V.25.0; IBM) and EmpowerStats (V.2018-05-05, copyright $2009 \mathrm{X} \& Y$ Solutions) were used for data analysis; a two-tailed $\mathrm{p}<0.05$ was considered statistically significant. R STUDIO was used for PSM to adjusting for confounding factors, and the PSM results were showed in online supplemental figures 2-7.

\section{RESULTS}

\section{Population and baseline characteristics}

The MIMIC-III database includes 2087 patients diagnosed with IAI according to the criteria mentioned earlier. Among these patients, 233 lacked weight data and were excluded from the study, and 14 patients with abnormal data records were excluded (eg, height value $>300 \mathrm{~m}$, survival time $<0$ days). MI was used to account for missing data on height in the remaining 1840 patients. Finally, after excluding 679 patients without height measurements, a total of 1161 patients were finally included in the study (figure 1).

Table 1 shows the baseline characteristics of patients grouped according to their BMI. There were 399 patients with BMI $<25 \mathrm{~kg} / \mathrm{m}^{2}, 357$ patients with BMI $25-30 \mathrm{~kg} /$ $\mathrm{m}^{2}$ and 405 patients with BMI $>30 \mathrm{~kg} / \mathrm{m}^{2}$, accounting for $34.37 \%, 30.75 \%$ and $34.88 \%$ of the patients, respectively. In the subgroup aged 45-64 years, the proportion of patients with an obese status was higher than that of patients with a normal and an overweight BMI $(42.96 \%$ vs $31.58 \%$ and $42.96 \%$ vs $33.61 \%$, respectively, $\mathrm{p}<0.05)$, while in the subgroup of patients older than 90 years, the result was the opposite $(1.73 \%$ vs $8.02 \%$ and $1.73 \%$ vs 5.32 , respectively, $\mathrm{p}<0.05)$. The proportion of women in the group of patients with an overweight status was lower than that in the other groups $(\mathrm{p}<0.001)$. There was no significant difference in ethnicity between the three groups $(p=0.183)$. However, there were significant differences between the three groups in regard to marital status and admission type $(\mathrm{p}=0.008$ and 0.009 , respectively). The group with BMI $<25 \mathrm{~kg} / \mathrm{m}^{2}$ had lower SOFA scores on the first day of admission than the obese group $(\mathrm{p}=0.039)$. However, there was no significant difference between the two groups with regard to SAPSII, SIRS, quick Sequential Organ Failure Assessment (qSOFA) score, Oxford Acute Severity of Illness Score score and Charlson Comorbidity Index ( $>0.05)$. Online supplemental table 2 shows the baseline characteristics after adjusting for confounding factors. After adjusting for confounding factors listed earlier, SOFA scores remained significantly different between groups $(\mathrm{p}<0.05)$.

\section{Univariate analysis of outcomes}

The mortality rates at different times of admission and the LOS of patients in the different BMI groups are shown in table 2.

The mortality of patients with BMI $<25 \mathrm{~kg} / \mathrm{m}^{2}$ was significantly higher than that of obese patients at 30 days after admission to the ICU $(18.55 \%$ vs $11.85 \%$,

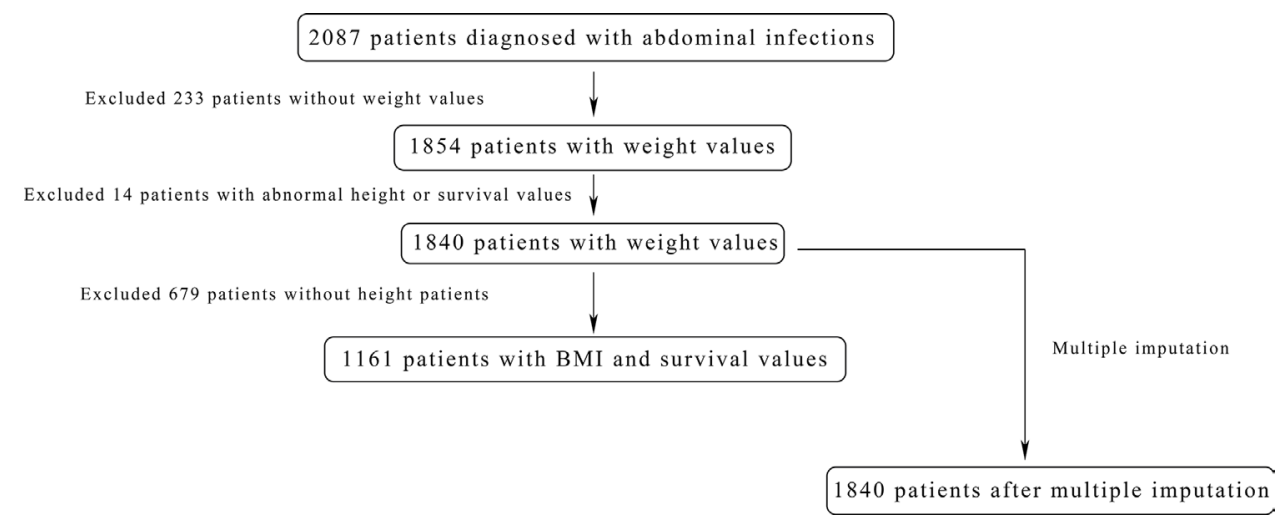

Figure 1 Flowchart of study cohort selection. BMI, body mass index. 
Table 1 Univariate analysis of baseline characteristics by BMI category

\begin{tabular}{|c|c|c|c|c|}
\hline & $\begin{array}{l}\text { BMI }<25 \mathrm{~kg} / \mathrm{m}^{2} \\
(\mathrm{n}=399)\end{array}$ & $\begin{array}{l}\text { BMI } 25-30 \mathrm{~kg} / \mathrm{m}^{2} \\
(\mathrm{n}=357)\end{array}$ & $\begin{array}{l}\mathrm{BMI}>30 \mathrm{~kg} / \mathrm{m}^{2} \\
(\mathrm{n}=405)\end{array}$ & $\mathrm{p}$ value \\
\hline Age, n (\%) & $66.56(50.16-80.25)^{\mathrm{a}}$ & $66.79(52.43-77.63)^{\mathrm{b}}$ & $62.97(51.94-72.92)^{\mathrm{b}}$ & $<0.001$ \\
\hline$<45$ & $64(16.04)$ & $47(13.17)$ & $60(14.81)$ & \\
\hline $45-64$ & $126(31.58)^{\mathrm{a}}$ & $120(33.61)^{\mathrm{a}}$ & $174(42.96)^{b}$ & \\
\hline $65-89$ & $177(44.36)$ & $171(47.90)$ & $164(40.49)$ & \\
\hline$>90$ & $32(8.02)^{\mathrm{a}}$ & $19(5.32)^{\mathrm{a}}$ & $7(1.73)^{b}$ & \\
\hline Female, n (\%) & $207(51.88)^{a}$ & $141(39.50)^{b}$ & $206(50.86)^{a}$ & 0.001 \\
\hline Ethnicity, n (\%) & & & & 0.183 \\
\hline White & $297(74.43)$ & $255(71.43)$ & $305(75.31)$ & \\
\hline Black & $40(10.03)$ & $36(10.08)$ & $38(9.38)$ & \\
\hline Hispanic or Latino & $11(2.76)$ & $14(3.92)$ & $11(2.72)$ & \\
\hline Asian & $7(1.75)$ & $11(3.08)$ & $1(0.25)$ & \\
\hline Other & $44(11.03)$ & $41(11.49)$ & $50(12.35)$ & \\
\hline Marital status, n (\%) & & & & 0.008 \\
\hline Married & $169(42.36)^{a}$ & $196(54.90)^{b}$ & $196(48.40)^{a, b}$ & \\
\hline Single/divorced/separated/unknown & $161(40.35)$ & $121(33.89)$ & $156(38.52)$ & \\
\hline Widowed & $69(17.29)$ & $40(11.20)$ & $53(13.09)$ & \\
\hline Admission type, n (\%) & & & & 0.009 \\
\hline Elective & $35(8.77)^{\mathrm{a}}$ & $50(14.01)^{a, b}$ & $64(15.80)^{b}$ & \\
\hline Emergency/urgent & $364(91.23)^{a}$ & $307(86.00)^{a, b}$ & $341(84.20)^{b}$ & \\
\hline Insurance type, n (\%) & & & & 0.604 \\
\hline Medicare/Medicaid & $261(65.41)$ & $236(66.11)$ & $250(61.73)$ & \\
\hline Private & $125(31.33)$ & $109(30.53)$ & $144(35.56)$ & \\
\hline Other & $13(3.26)$ & $12(3.36)$ & $11(2.72)$ & \\
\hline SOFA & $5(2-7)^{a}$ & $5(3-7)^{a, b}$ & $5(3-8)^{b}$ & 0.039 \\
\hline SAPSII & $40(30-50)$ & $39(29-50)$ & 38 (28-49) & 0.473 \\
\hline SIRS & $3(3-4)$ & $3(3-4)$ & $3(3-4)$ & 0.786 \\
\hline qSOFA & $2(1-2)$ & $2(1-2)$ & $2(1-2)$ & 0.185 \\
\hline OASIS & $34(27-40)$ & $33(28-41)$ & $34(27-41)$ & 0.941 \\
\hline Charlson Comorbidity Index & $1(0-3)$ & $2(1-3)$ & $1(0-3)$ & 0.719 \\
\hline
\end{tabular}

The letters $a$ and $b$ were used to indicate the difference between groups and if there is statistical difference between the two subgroups, different letters shall be used for identification.

BMI, body mass index; OASIS, Oxford Acute Severity of IIIness Score; qSOFA, quick Sequential Organ Failure Assessment; SAPSII, Simplified Acute Physiology Score II; SIRS, systemic inflammatory response syndrome; SOFA, Sequential Organ Failure Assessment.

respectively, $\mathrm{p}=0.016$ ), which was the same at 90 days after admission to the ICU $(28.07 \%$ vs $20.74 \%$, respectively, $\mathrm{p}=0.048$ ). In addition, the median LOS for patients with a BMI $<25,25-30$ and $>30 \mathrm{~kg} / \mathrm{m}^{2}$ in the ICU was 3.13 , 3.59 and 4.93 days, respectively $(\mathrm{p}<0.001)$, and the obese group spent significantly more time in the ICU than the former two groups $(p<0.05)$. However, in the subgroup analysis, only those patients who did not die in the ICU showed significant differences, while those who died did not $(\mathrm{p}<0.001$ and $\mathrm{p}=0.166$, respectively). After adjusting for confounding factors, the LOS in the ICU of obese patients was still significantly longer than that of the other two groups $(p<0.001$, online supplemental table 3$)$. In subgroup analysis, the conclusion was the same as above, which may be due to the bias caused by the number of deceased patients.

The K-M curve for the 90-day survival by BMI is shown in figure 2. This shows that the group with an overweight and obese BMI had a significant survival advantage $(\mathrm{p}<0.001$ by log-rank test). After excluding patients with $\mathrm{BMI}<18.5 \mathrm{~kg} / \mathrm{m}^{2}$, the K-M curve was rebuilt (online supplemental figure 8 ), and the result did not change ( $\mathrm{p}<0.001$ by log-rank test).

The 90-day survival curve stratified according to the BMI in patients with and without sepsis is shown in figure 3 . In different subgroups, patients with a BMI $>25 \mathrm{~kg} / \mathrm{m}^{2}$ had significantly better survival than those with a BMI $<25 \mathrm{~kg} /$ $\mathrm{m}^{2}(\mathrm{p}<0.001$ and $\mathrm{p}<0.05$, respectively, by log-rank test $)$. 
Table 2 Univariate analysis of mortality and length of stay by BMI category

\begin{tabular}{|c|c|c|c|c|}
\hline & $\begin{array}{l}\text { BMI <25 kg/m² } \\
(n=399)\end{array}$ & $\begin{array}{l}\text { BMI } 25-30 \mathrm{~kg} / \mathrm{m}^{2} \\
(\mathrm{n}=357)\end{array}$ & $\begin{array}{l}\text { BMI >30 kg/m } / \mathrm{m}^{2} \\
(\mathrm{n}=405)\end{array}$ & $p$ value \\
\hline \multicolumn{5}{|l|}{ Mortality, n (\%) } \\
\hline 30-day mortality & $74(18.55)^{a}$ & $46(12.89)^{a, b}$ & $48(11.85)^{b}$ & 0.016 \\
\hline 90-day mortality & $112(28.07)^{\mathrm{a}}$ & $83(23.25)^{a, b}$ & $84(20.74)^{b}$ & 0.048 \\
\hline \multicolumn{5}{|l|}{ Length of stay, day (IQR) } \\
\hline Hospital LOS & $14.9(8.4-28.6)$ & $15.4(7.9-27.0)$ & $16.2(9.1-29.8)$ & 0.137 \\
\hline Living patients $(n=962)$ & $15.0(8.7-28.6)$ & $14.3(7.9-24.9)$ & $16.4(9.3-29.8)$ & 0.059 \\
\hline Dead patients $(n=201)$ & $13.9(5.4-29.3)$ & $17.9(7.1-33.3)$ & $13.7(6.2-30.7)$ & 0.412 \\
\hline ICU LOS & $3.1(1.8-7.8)^{\mathrm{a}}$ & $3.6(1.9-8.9)^{a}$ & $4.9(2.2-13.6)^{b}$ & $<0.001$ \\
\hline Living patients $(n=1036)$ & $3.1(1.7-6.7)^{\mathrm{a}}$ & $3.3(1.8-7.7)^{a}$ & $4.7(2.2-13.2)^{b}$ & $<0.001$ \\
\hline
\end{tabular}

The letters $a$ and $b$ were used to indicate the difference between groups and if there is statistical difference between the two subgroups, different letters shall be used for identification.

BMI, body mass index; ICU, intensive care unit; LOS, length of stay.

We also compared the use of mechanical ventilation, vasoactive drugs and dialysis between the three groups as shown in table 3 . The proportion of patients with an obese BMI who needed mechanical ventilation was higher than that in patients with a normal BMI $(61.48 \%$ vs $52.38 \%$, $\mathrm{p}=0.034$ ). However, in regard to the use of vasoactive drugs and dialysis, there was no significant difference between the three groups. After adjusting for confounding factors, there was no significant difference in the use of mechanical ventilation (online supplemental table 4).

The results of several laboratory tests stratified by BMI are shown in table 4. Significant differences were observed in the HGB, WBC, Cl, CRE and GLU levels between the three groups $(\mathrm{p}=0.048,0.035,0.007$, 0.001 and $<0.001$, respectively). After adjusting for confounding factors, there was no significant difference

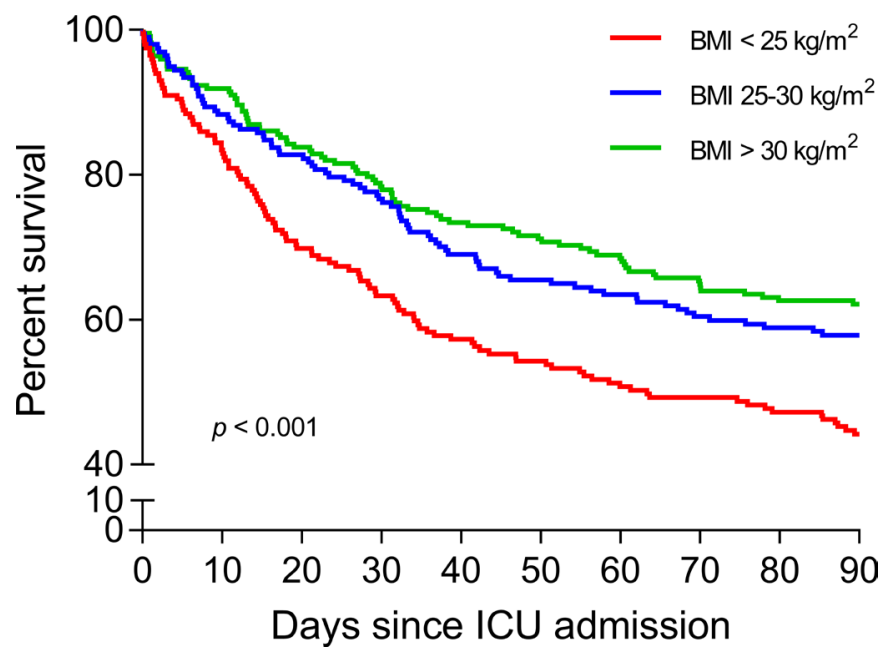

Figure 2 Kaplan-Meier curve for 90-days survival stratified by BMI. Figure 2 represents 90-days Kaplan-Meier curves stratified by $\mathrm{BMI}$ in three groups, $\mathrm{p}<0.001$ by log-rank test. BMI, body mass index; ICU, intensive care unit. in HGB levels among the groups, but there was a significant difference in Na levels $(\mathrm{p}=0.042$, online supplemental table 5).

\section{Cox proportional hazards analyses of 90-day mortality}

We imported variables with $p$ values $<0.10$ in univariate analysis into Cox proportional hazards analyses after testing the collinearity of the variables. When BMI was employed as a continuous variable, the adjusted HR values in the four models were $0.98(0.97,0.99), 0.97$ $(0.96,0.99), 0.97(0.96,0.99)$ and $0.96(0.95,0.98)$. When BMI was applied as a classification variable, it was also associated with the 90-day mortality of patients with IAIs (table 5). However, in the multi-factor regression analysis of the subgroup analysis of acute pancreatitis and other patients, when BMI was employed as a continuous variable, the adjusted HR values were $0.98(0.95,1.00)$ and $0.97(0.95,0.99)$ for acute pancreatitis patients and other patients, respectively (online supplemental table 6 ), while both before and after the adjustment, the HR values were almost the same, and the $p$ value was close to 0.05 , which may be due to the sample size ( $n=321$ and $n=355$, respectively after adjustment).

Considering the high proportion of missing height value in the patient group, we conducted MI with height values, and calculated the BMI with weight values and imputed height values. Whether BMI was employed as a continuous variable or a classification variable, the adjusted HR value in the models showed that BMI was a protective factor of the 90-day mortality in patients with IAIs (online supplemental table 7). The results in online supplemental table 8 show that in the imputed data, BMI was not a protective factor in patients with acute pancreatitis, but it was still a protective factor in other patients with IAI. Excluding acute pancreatitis patients from the analysis did not affect the results. 

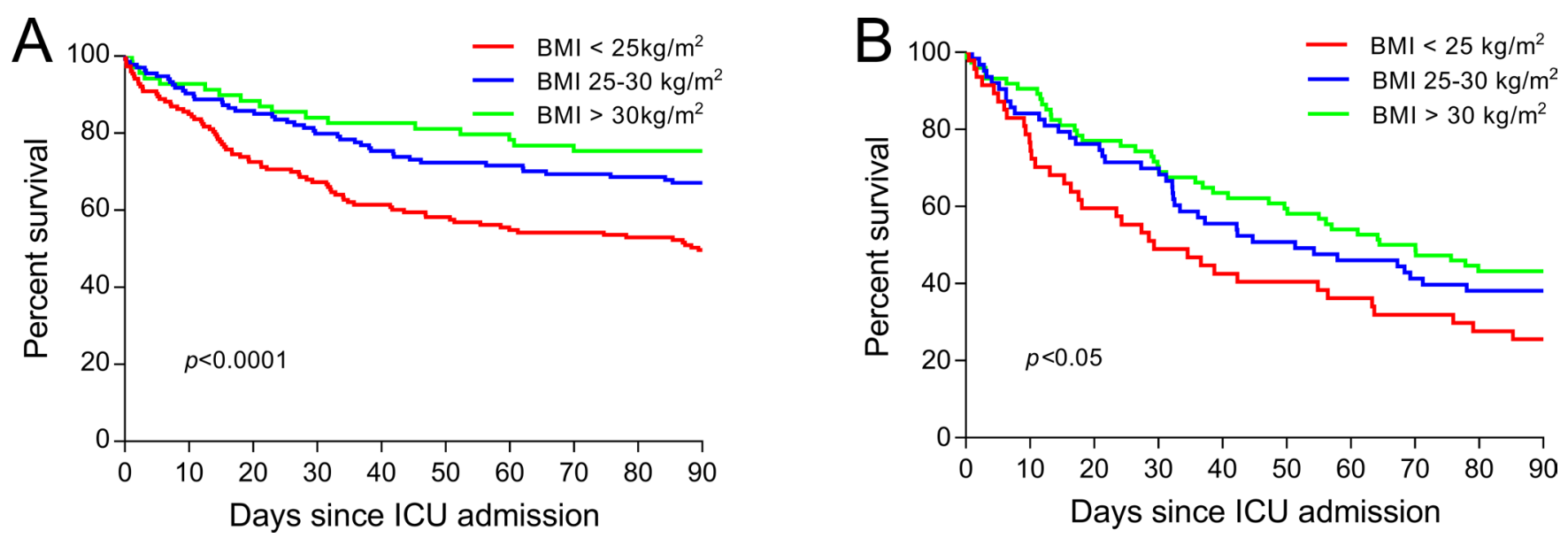

Figure 3 90-day Kaplan-Meier curve of patients without (A) and with (B) sepsis stratified by BMI. (A) and (B) represent 90-day Kaplan-Meier curves of patients without and with sepsis, respectively. In log-rank test $p<0.001, p<0.05$, respectively. BMI, body mass index; ICU, intensive care unit.

\section{DISCUSSION}

In this retrospective study, we used the MIMIC-III database to study the relationship between BMI and the shortterm mortality of patients with abdominal infection. By comparing the survival curve and 90-day mortality of the three groups, it was found that the short-term prognosis of overweight $\left(25-30 \mathrm{~kg} / \mathrm{m}^{2}\right)$ and obese $\left(>30 \mathrm{~kg} / \mathrm{m}^{2}\right)$ patients were significantly better than that in the normal group.

By comparing the baseline characteristics of the three groups of patients, a significant difference was observed in the overall age composition of the three groups and in the 45-64 and >90 age subgroups between the three groups, and this statistical difference between subgroups still exists after adjusting for confounding factors. Subsequently, in our study, overweight patients were more likely to be men. However, previous studies have shown that obese cohorts tend to be younger and have a higher female prevalence. ${ }^{18}$ The possible cause of this discrepancy, as mentioned in previous studies, could be that male patients are more likely to develop abdominal infections such as appendicitis, and smoking is a probable cause for this increased risk. ${ }^{19} 20$

Currently, studies on the association of obesity with patients outcomes are mainly focused on sepsis, and the results are ambiguous and contradictory. ${ }^{21-23}$ In this study, we expanded the scope of this relationship to study the association between BMI and the short-term outcomes of patients with IAIs. Our finding shows that obese patients had a higher SOFA score at admission, indicating a worse degree of organ failure than that in patients with a lower BMI, and the incidence of sepsis events was higher in patients with a higher BMI. Previous studies have shown that people who were overweight or obese had higher susceptibility to developing postsurgical infections, and respiratory tract infections and tended to develop more severe infections, which is consistent with the results of our study; however, the short-term outcome of these patients was better. ${ }^{24}{ }^{25}$ The same contradiction exists in our laboratory test results. According to a previous study, serum CRE was an independent risk factor for clinical failure, but in our cohort, obese patients had significantly higher CRE values, which should lead to a worse clinical outcome. ${ }^{26}$ Previous studies also showed that CRE minimums at baseline were considered a predictor of shortterm mortality. ${ }^{27}$ However, some studies have reported that CRE can predict multiple organ failure. ${ }^{28}$ This may be related to the baseline characteristics of our study population, and CRE level no longer appears as an independent factor that associated with the prognosis after adjusting for the baseline characteristics. Among the laboratory tests included in our study, the HGB in the obese and overweight group was higher than that in the other group. Contrarily, a higher HGB value can provide more

Table 3 Univariate analysis of requirement of organ support therapy by BMI category

\begin{tabular}{|c|c|c|c|c|}
\hline & BMI <25 kg/m² $(n=399)$ & BMI 25-30 kg/m² $(n=357)$ & BMI $>30 \mathrm{~kg} / \mathrm{m}^{2}(\mathrm{n}=405)$ & $\begin{array}{l}p \\
\text { value }\end{array}$ \\
\hline Ventilation, n (\%) & $209(52.38)^{a}$ & $203(56.86)^{a, b}$ & $249(61.48)^{b}$ & 0.034 \\
\hline Vasoactive agent, n (\%) & 138 (34.59) & $123(34.45)$ & $143(35.31)$ & 0.964 \\
\hline
\end{tabular}


Table 4 Univariate analysis of laboratory examination by BMI category

\begin{tabular}{|c|c|c|c|c|}
\hline & BMI $<25 \mathrm{~kg} / \mathrm{m}^{2}$ & BMI $25-30 \mathrm{~kg} / \mathrm{m}^{2}$ & $\mathrm{BMI}>30 \mathrm{~kg} / \mathrm{m}^{2}$ & $p$ value \\
\hline WBC $\left(\times 10^{9} / L\right)$ & $10.1(6.2-14.9)^{a, b}, n=396$ & $9.7(6.5-13.8)^{a}, n=355$ & $10.9(7.1-15.2)^{b}, n=404$ & 0.035 \\
\hline CRE (mg/dL) & $1.1(0.8-1.8)^{a}, n=396$ & $1.2(0.9-2.2)^{\mathrm{b}}, \mathrm{n}=355$ & $1.3(0.9-2.2)^{b}, n=405$ & 0.001 \\
\hline BUN (mg/dL) & 24 (16-39), n=396 & 25 (16-41), n=355 & 25 (16-44), n=405 & 0.610 \\
\hline $\mathrm{Cl}(\mathrm{mEq} / \mathrm{L})$ & $109(105-113)^{a}, n=396$ & $109(105-112)^{a}, n=356$ & $108(104-111)^{b}, n=405$ & 0.007 \\
\hline $\mathrm{K}(\mathrm{mEq} / \mathrm{L})$ & $3.6(3.2-4.0), n=396$ & $3.7(3.3-4.0), n=356$ & 3.7 (3.4-4.1), n=405 & 0.168 \\
\hline $\mathrm{Na}(\mathrm{mEq} / \mathrm{L})$ & 136 (132-139), n=396 & 136 (133-139), n=356 & 136 (133.5-139), n=405 & 0.235 \\
\hline GLU (mg/dL) & $153(122-194)^{a}, n=396$ & $154(125-195.75)^{\mathrm{a}}, \mathrm{n}=356$ & $170(136.5-226)^{b}, n=405$ & $<0.001$ \\
\hline
\end{tabular}

The letters $a$ and $b$ were used to indicate the difference between groups and if there is statistical difference between the two subgroups, different letters shall be used for identification.

ALB, albumin; BIL, bilirubin; BMI, body mass index; BUN, urea nitrogen; Cl, chlorine; CRE, creatinine; GLU, glucose; HGB, haemoglobin; K, potassium; LAC, lactate; Na, sodium; PLT, platelet count; WBC, white cell count.

oxygen to tissues and reduce hypoxia, whereas obese patients may originally have a higher HGB value, they may therefore confer a survival advantage. After adjusted, there was no significant difference in HGB levels, but the median of HGB in the obese and overweight group still higher than that in the other group. Furthermore, it was found that patients without sepsis but with IAIs can also benefit from a higher BMI. This shows that BMI has a protective effect not only in patients with severe conditions, such as sepsis patients but also in patients with a milder condition. However, once sepsis occurs in patients with abdominal infection, the short-term prognosis will be significantly worse.

Our study also found that patients with a higher BMI had a higher probability of receiving mechanical ventilation, which was also reported in the previous studies. ${ }^{29}$ This may be related to the impact of obesity on the respiratory system, obese patients tend to have higher respiratory rates and lower tidal volumes, and lung volumes tend to be decreased, especially the expiratory reserve volume. ${ }^{30}$ BMI was associated with an increased risk of acute respiratory distress syndrome in a weight-dependent manner but was not associated with mortality. ${ }^{31}$ As mentioned earlier, obese patients are also more likely to receive mechanical ventilation as well as the attention of medical staff. ${ }^{32}$ In summarise, patients with a higher BMI have a poor health foundation and are more likely to progress to critical illness, but there are also some indicators, such as HGB level that may prevent organ failure caused by critical illness in this process. In addition, they are more likely to receive advanced modes of mechanical ventilation, dialysis, liver function support and medical resources.

In the final Cox regression model, BMI remained a protective factor after adjusting for confounding variables. This is a phenomenon called the obesity paradox, which means that overweight and obese patients are recognised as they often have more basic diseases, such as hypertension, cardiovascular disease and diabetes. Their general health is also worse than that of patients with a normal $\mathrm{BMI}$, and some studies have shown that BMI is associated with an incidence rate of more than 20 types of cancers, but BMI still shows protective effects and improves the prognosis of patients. The reasons and underlying mechanisms have not been clarified. ${ }^{33}$ Some studies have suggested that patients with obesity-associated comorbidities, such as hypertension may require less vasoactive drugs and fluid resuscitation in the treatment process; severe IAIs can lead to sepsis that requires fluid resuscitation, and a restrictive fluid strategy would reduce the burden of heart or lung injuries to protect organ function. ${ }^{34}$ Drugs that patients with cardiovascular disease take in the long-term, such as aspirin, might play a protective role in IAIs, antiplatelet drugs can inhibit coagulation and inflammatory reactions in models of sepsis, reducing damage to organ function; and clinical studies also suggest that aspirin may improve the prognosis of patients with sepsis. ${ }^{36}$

The protective effect of diabetes may occur through an unidentified hormonal intermediary, or it may be caused by antidiabetic drugs such as rosiglitazone taken by diabetic patients, which increases the serum levels of adiponectin, thus resulting in a better prognosis. ${ }^{37}{ }^{38} \mathrm{~A}$ recent study also indicated an association between metformin use prior to admission and lower mortality in septic adult patients with diabetes mellitus. Metformin may supply higher amounts of LAC, serving as an energetic carbon source, thus making energy available to ischaemic tissue. ${ }^{39} 40$ Second, in acute catabolic reactions caused by IAIs, stored fuel and nutritional reserves might be critical in obese patients. In our study, the 
Table 5 Result of the Cox proportional hazard regression analysis

\begin{tabular}{|c|c|c|}
\hline Exposure & Non-adjusted HR, $p$ value & Adjusted HR, $p$ value \\
\hline \multicolumn{3}{|l|}{ Model 1} \\
\hline BMI & $0.98(0.97-0.99),<0.0001$ & $0.98(0.97,0.99), 0.0001$ \\
\hline \multicolumn{3}{|l|}{ BMI } \\
\hline$<25, \mathrm{~kg} / \mathrm{m}^{2}$ & 1.00 (Reference) & 1.00 (Reference) \\
\hline $25-30, \mathrm{~kg} / \mathrm{m}^{2}$ & $0.78(0.64,0.96), 0.0158$ & $0.78(0.64,0.95), 0.0148$ \\
\hline$>30, \mathrm{~kg} / \mathrm{m}^{2}$ & $0.68(0.56,0.83), 0.0001$ & $0.68(0.56,0.83), 0.0002$ \\
\hline \multicolumn{3}{|l|}{ Model 2} \\
\hline BMI & $0.98(0.97,0.99),<0.0001$ & 0.97 (0.96, 0.99), 0.0008 \\
\hline \multicolumn{3}{|l|}{ BMI } \\
\hline$<25, \mathrm{~kg} / \mathrm{m}^{2}$ & 1.00 (Reference) & 1.00 (Reference) \\
\hline $25-30, \mathrm{~kg} / \mathrm{m}^{2}$ & $0.78(0.64,0.96), 0.0158$ & 0.79 (0.61, 1.02), 0.0729 \\
\hline$>30, \mathrm{~kg} / \mathrm{m}^{2}$ & $0.68(0.56,0.83), 0.0001$ & 0.66 (0.51, 0.86), 0.0021 \\
\hline \multicolumn{3}{|l|}{ Model 3} \\
\hline BMI & $0.98(0.97,0.99),<0.0001$ & 0.97 (0.96, 0.99), 0.0009 \\
\hline \multicolumn{3}{|l|}{ BMI } \\
\hline$<25, \mathrm{~kg} / \mathrm{m}^{2}$ & 1.00 (Reference) & 1.00 (Reference) \\
\hline $25-30, \mathrm{~kg} / \mathrm{m}^{2}$ & 0.78 (0.64-0.96), 0.0158 & $0.72(0.56,0.94), 0.0152$ \\
\hline$>30, \mathrm{~kg} / \mathrm{m}^{2}$ & $0.68(0.56,0.83), 0.0001$ & $0.66(0.50,0.86), 0.0022$ \\
\hline \multicolumn{3}{|l|}{ Model 4} \\
\hline BMI & $0.98(0.97,0.99),<0.0001$ & $0.96(0.95,0.98),<0.0001$ \\
\hline \multicolumn{3}{|l|}{ BMI } \\
\hline$<25, \mathrm{~kg} / \mathrm{m}^{2}$ & 1.00 (Reference) & 1.00 (Reference) \\
\hline $25-30, \mathrm{~kg} / \mathrm{m}^{2}$ & $0.78(0.64,0.96), 0.0158$ & $0.54(0.40,0.73),<0.0001$ \\
\hline$>30, \mathrm{~kg} / \mathrm{m}^{2}$ & $0.68(0.56,0.83), 0.0001$ & $0.48(0.36,0.65),<0.0001$ \\
\hline
\end{tabular}

Model 1: adjusted for gender; admission age; SOFA; admission type; insurance; marital status; ethnicity.

Model 2: adjusted for gender; admission age; SOFA; admission type; insurance; marital status; ethnicity; HGB; GLU; ALB.

Model 3: adjusted for gender; admission age; SOFA; admission type; insurance; marital status; ethnicity; HGB; GLU; ALB; Charlson Comorbidity Index.

Model 4: adjusted for Charlson Comorbidity Index.

ALB, albumin; BMI, body mass index; GLU, glucose; HGB, haemoglobin; SOFA, Sequential Organ Failure Assessment.

higher CRE values of overweight and obese patients also support this standpoint; however, in IAIs, due to abrosia and acute gastrointestinal dysfunction, the energy supply is frequently insufficient. ${ }^{41}$ Third, adipocytes can release adipokines and inflammatory factors such as interleukin 10 and leptin, which can regulate the immune response and improve the prognosis of patients with an acute inflammatory response. ${ }^{42} \mathrm{~A}$ previous study indicated that lipopolysaccharides may be sequestered in adipose tissue via the very-low-density lipoprotein receptor, and this sequestration may contribute to improved sepsis survival; when BMI was greater than $25 \mathrm{~kg} / \mathrm{m}^{2}$, this effect was accentuated. ${ }^{43}$ In addition, the difference in nursing level may also be associated with the prognosis of obese patients. As mentioned earlier, obese patients often suffer from more basic diseases and complications, and they are more likely to receive the attention of nursing staff, receiving more active treatment. ${ }^{32}$ Finally, previous studies suggest that BMI is not the best indicator to accurately evaluate obesity, which leads to the obesity paradox. ${ }^{44}$

This study has several limitations. First, this was a retrospective single centre study. Similar to other observational studies, it is difficult to completely exclude the influence of residual confounding factors. Second, due to the characteristics of the database itself, a considerable number of patients' data were missing, especially various laboratory test data, which may cause selection bias; however, we did not introduce the missing indicators into the final Cox regression model. Third, in this study, we only obtained the baseline characteristic information of patients and some of their laboratory examination results within 24 hours after admission, but did not specifically study their infection and treatment process (such as the use of antibiotics), and the disparate interventions in the two groups with regard to these factors may lead to deviations in our results. Next, given the observational nature 
of this study, we can not determine causality between BMI and mortality. Finally, the total sample size of the database was very large, but the number of subgroups in our study was relatively small, which may also affect the reliability of our results.

\section{CONCLUSION}

IAI patients with an overweight and obese status have lower 90-day mortality than patients with a normal BMI. The protection of BMI exists not only in patients with severe conditions, such as sepsis patients, but also in patients with milder conditions.

Acknowledgements We are indebted to all individuals who participated in or helped with this research project.

Contributors QL participated in the research design, data analysis and writing of the paper; YT participated in the data collecting; QL, YT contributed equally to this work. SL participated in data analysis and revising of the paper; KY participated in the data cleaning; CL and JZ provided substantial advice in designing the study and assisting in the division of labour, writing and revising the paper.

Funding The authors have not declared a specific grant for this research from any funding agency in the public, commercial or not-for-profit sectors.

Competing interests None declared.

Patient consent for publication Not required.

Ethics approval The use of MIMIC-III database was under the approval from the review boards of the Massachusetts Institute of Technology and Beth Israel Deaconess Medical Center. The database is freely available, in that any researcher who accepts the data-use agreement and has completed the 'protecting human subjects' training can apply for permission to access the data. We did not need patient consent or ethics approval, and permission to participate was also not appropriate, because our review was a retrospective study of data reuse, and the message of the patients was anonymous.

Provenance and peer review Not commissioned; externally peer reviewed.

Data availability statement Data are available in a public, open access repository. MIMIC-III, a freely accessible critical care database. Johnson AEW, Pollard TJ, Shen L, Lehman L, Feng M, Ghassemi M, Moody B, Szolovits P, Celi LA, and Mark RG. Scientific Data (2016). DOI: 10.1038/sdata.2016.35. Available from: http://www. nature.com/articles/sdata201635 and https://mimic.mit.edu/.

Supplemental material This content has been supplied by the author(s). It has not been vetted by BMJ Publishing Group Limited (BMJ) and may not have been peer-reviewed. Any opinions or recommendations discussed are solely those of the author(s) and are not endorsed by BMJ. BMJ disclaims all liability and responsibility arising from any reliance placed on the content. Where the content includes any translated material, BMJ does not warrant the accuracy and reliability of the translations (including but not limited to local regulations, clinical guidelines, terminology, drug names and drug dosages), and is not responsible for any error and/or omissions arising from translation and adaptation or otherwise.

Open access This is an open access article distributed in accordance with the Creative Commons Attribution Non Commercial (CC BY-NC 4.0) license, which permits others to distribute, remix, adapt, build upon this work non-commercially, and license their derivative works on different terms, provided the original work is properly cited, appropriate credit is given, any changes made indicated, and the use is non-commercial. See: http://creativecommons.org/licenses/by-nc/4.0/.

\section{ORCID iD}

Jingyao Zhang http://orcid.org/0000-0002-8227-9396

\section{REFERENCES}

1 Sartelli M, Chichom-Mefire A, Labricciosa FM, et al. The management of intra-abdominal infections from a global perspective: 2017 WSES guidelines for management of intra-abdominal infections. World J Emerg Surg 2017;12:29.
2 Hecker A, Reichert M, Reuß CJ, et al. Intra-Abdominal sepsis: new definitions and current clinical standards. Langenbecks Arch Surg 2019;404:257-71.

3 Eggimann P, Pittet D. Infection control in the ICU. Chest 2001;120:2059-93.

4 Shirah GR, O'Neill PJ. Intra-Abdominal infections. Surg Clin North Am 2014;94:1319-33.

5 Gonzalez MC, Correia MITD, Heymsfield SB. A requiem for BMI in the clinical setting. Curr Opin Clin Nutr Metab Care 2017;20:314-21.

6 Flegal KM, loannidis JPA, Doehner W. Flawed methods and inappropriate conclusions for health policy on overweight and obesity: the global BMI mortality collaboration meta-analysis. $J$ Cachexia Sarcopenia Muscle 2019;10:9-13.

7 Heetun A, Cutress RI, Copson ER. Early breast cancer: why does obesity affect prognosis? Proc Nutr Soc 2018;77:369-81.

8 Secord AA, Hasselblad V, Von Gruenigen VE, et al. Body mass index and mortality in endometrial cancer: a systematic review and metaanalysis. Gynecol Oncol 2016;140:184-90.

9 Barone M, Viggiani MT, Losurdo G, et al. Systematic review with meta-analysis: post-operative complications and mortality risk in liver transplant candidates with obesity. Aliment Pharmacol Ther 2017;46:236-45.

10 Wang Y, Beydoun MA. The obesity epidemic in the United States-gender, age, socioeconomic, racial/ethnic, and geographic characteristics: a systematic review and meta-regression analysis. Epidemiol Rev 2007;29:6-28.

11 Kalantar-Zadeh K, Abbott KC, Salahudeen AK, et al. Survival advantages of obesity in dialysis patients. Am J Clin Nutr 2005;81:543-54.

12 Chlebowski RT, Grosvenor M, Lillington L, et al. Dietary intake and counseling, weight maintenance, and the course of HIV infection. $J$ Am Diet Assoc 1995;95:428-35.

13 Johnson AEW, Pollard TJ, Shen L, et al. MIMIC-III, a freely accessible critical care database. Sci Data 2016;3:160035.

14 Han D, Zhang L, Zheng S, et al. Prognostic value of blood urea Nitrogen/Creatinine ratio for septic shock: an analysis of the MIMICIII clinical database. Biomed Res Int 2021;2021:1-16.

15 Guo Q, Li H, Ouyang H, et al. Heart rate fluctuation and mortality in critically ill myocardial infarction patients: a retrospective cohort study. Front Cardiovasc Med 2021;8:577742.

16 Zhang W, Wang Y, Li W, et al. The association between the baseline and the change in neutrophil-to-lymphocyte ratio and short-term mortality in patients with acute respiratory distress syndrome. Front Med 2021;8:636869.

17 Park S-Y, Freedman ND, Haiman CA, et al. Association of coffee consumption with total and cause-specific mortality among Nonwhite populations. Ann Intern Med 2017;167:228-35.

$18 \mathrm{Li} \mathrm{S}, \mathrm{Hu} \mathrm{X}, \mathrm{Xu} \mathrm{J}$, et al. Increased body mass index linked to greater short- and long-term survival in sepsis patients: a retrospective analysis of a large clinical database. Int $J$ Infect Dis 2019;87:109-16.

19 Ferris M, Quan S, Kaplan BS. The global incidence of appendicitis: a systematic review of population-based studies. Ann Surg 2017;266:237-41.

20 Montgomery SM, Pounder RE, Wakefield AJ. Smoking in adults and passive smoking in children are associated with acute appendicitis. Lancet 1999;353:379.

21 Trivedi V, Bavishi C, Jean R. Impact of obesity on sepsis mortality: a systematic review. J Crit Care 2015;30:518-24.

22 Wang S, Liu X, Chen Q, et al. The role of increased body mass index in outcomes of sepsis: a systematic review and meta-analysis. BMC Anesthesiol 2017;17:118.

23 Wang $\mathrm{H}$, Shi Y, Bai Z-H, et al. Higher body mass index is not a protective risk factor for 28-days mortality in critically ill patients with acute kidney injury undergoing continuous renal replacement therapy. Ren Fail 2019;41:726-32.

24 Maccioni L, Weber S, Elgizouli M, et al. Obesity and risk of respiratory tract infections: results of an infection-diary based cohort study. BMC Public Health 2018;18:271.

25 Dhurandhar NV, Bailey D, Thomas D. Interaction of obesity and infections. Obes Rev 2015;16:1017-29.

26 White BP, Wagner JL, Barber KE, et al. Risk factors for failure in complicated intraabdominal infections. South Med J 2018;111:125-32.

27 Thongprayoon C, Cheungpasitporn W, Kittanamongkolchai W, et al. Optimum methodology for estimating baseline serum creatinine for the acute kidney injury classification. Nephrology 2015;20:881-6.

28 Dewar DC, Tarrant SM, King KL, et al. Changes in the epidemiology and prediction of multiple-organ failure after injury. $J$ Trauma Acute Care Surg 2013;74:774-9. 
29 Sakr Y, Alhussami I, Nanchal R, et al. Being overweight is associated with greater survival in ICU patients: results from the intensive care over nations audit. Crit Care Med 2015;43:2623-32.

30 Littleton SW. Impact of obesity on respiratory function. Respirology 2012;17:43-9.

31 Gong MN, Bajwa EK, Thompson BT, et al. Body mass index is associated with the development of acute respiratory distress syndrome. Thorax 2010;65:44-50.

32 O'Brien JM, Philips GS, Ali NA, et al. The association between body mass index, processes of care, and outcomes from mechanical ventilation: a prospective cohort study. Crit Care Med 2012;40:1456-63.

33 Bhaskaran K, Douglas I, Forbes H, et al. Body-Mass index and risk of 22 specific cancers: a population-based cohort study of $5 \cdot 24$ million UK adults. Lancet 2014;384:755-65.

34 Wacharasint P, Boyd JH, Russell JA, et al. One size does not fit all in severe infection: obesity alters outcome, susceptibility, treatment, and inflammatory response. Crit Care 2013;17:R122.

35 Stewart RM, Park PK, Hunt JP, et al. Less is more: improved outcomes in surgical patients with conservative fluid administration and central venous catheter monitoring. J Am Coll Surg 2009;208:725-35.

36 Wang $\mathrm{Y}$, Ouyang $\mathrm{Y}$, Liu B, et al. Platelet activation and antiplatelet therapy in sepsis: a narrative review. Thromb Res 2018;166:28-36.

37 Kuperman EF, Showalter JW, Lehman EB, et al. The impact of obesity on sepsis mortality: a retrospective review. BMC Infect Dis 2013;13:377.
38 Uji Y, Yamamoto H, Tsuchihashi $\mathrm{H}$, et al. Adiponectin deficiency is associated with severe polymicrobial sepsis, high inflammatory cytokine levels, and high mortality. Surgery 2009;145:550-7.

39 Liang H, Ding X, Li L, et al. Association of preadmission metformin use and mortality in patients with sepsis and diabetes mellitus: a systematic review and meta-analysis of cohort studies. Crit Care 2019;23:50

40 Hui S, Ghergurovich JM, Morscher RJ, et al. Glucose feeds the TCA cycle via circulating lactate. Nature 2017;551:115-8.

41 Niedziela J, Hudzik B, Niedziela N, et al. The obesity paradox in acute coronary syndrome: a meta-analysis. Eur J Epidemiol 2014;29:801-12.

42 McLaughlin T, Deng A, Yee G, et al. Inflammation in subcutaneous adipose tissue: relationship to adipose cell size. Diabetologia 2010;53:369-77.

43 Shimada T, Topchiy E, Leung AKK, et al. Very low density lipoprotein receptor sequesters lipopolysaccharide into adipose tissue during sepsis. Crit Care Med 2020;48:41-8.

44 Xing Z, Tang L, Chen J, et al. Association of predicted lean body mass and fat mass with cardiovascular events in patients with type 2 diabetes mellitus. CMAJ 2019;191:E1042-8.

45 Xing Z, Peng Z, Wang $X$, et al. Waist circumference is associated with major adverse cardiovascular events in male but not female patients with type-2 diabetes mellitus. Cardiovasc Diabetol 2020;19:39. 